\title{
Seasonal water quality and trophic status of shallow lentic waters and their association with water levels
}

\begin{abstract}
Extreme hydro-climatic changes associated with floods and drought greatly influence the ecosystem dynamic of tropical lakes in Malaysia, resulting in negative impacts on their water quality and trophic status. This study examined the seasonal changes in water quality and trophic state connected to hydro-ecological changes in a natural lake and two reservoirs. Water levels in the three water bodies varied with changes in rainfall regime, and water regulation for irrigation or water supply. Multivariate analysis of variance showed a significant relationship between season and temperature, $\mathrm{pH}$, conductivity, total nitrogen and chlorophyll-a ( $\mathrm{p}<0.05)$. Drought events and the associated period of low water levels were characterized by high temperature, conductivity and chlorophyll-a levels in these shallow lakes, which probably led to high photosynthetic rates with concomitant increase in dissolved oxygen and $\mathrm{pH}$ and decrease in total nitrogen concentration. Elevated chlorophyll-a and total phosphorus concentrations were also associated with drought events and the decrease in water level in Bukit Merah Reservoir, possibly due to the release of phosphorus from internal loading resulting from sediment re-suspension by wind. Salinity increase in Durian Tunggal Reservoir during dry season was possibly due to seawater intrusion into river. During the rainy season, transparency in Bera Lake and Bukit Merah Reservoir was strongly influenced by the influxes of the main river that transported elevated levels of suspended solids and nutrients.
\end{abstract}

Keyword: Climate variability; Drought; Hydro-ecological dynamic; Lakes; Tropical limnology 